\title{
KARAKTERISTIK SISWA TENTANG PENCEGAHAN FIBROADENOMA MAMMAE (FAM)
}

\author{
Desy Susanti ${ }^{1}$, Rini Mustikasari Kurnia Pratama ${ }^{2}$ \\ Sekolah Tinggi IImu Kesehatan Keluarga Bunda Jambi ${ }^{12}$ \\ e-mail: desisusanti.081282@gmail.com ${ }^{1}$,rini.mazin@gmail.com ${ }^{2}$
}

\begin{abstract}
One of the non-communicable diseases is Fibro Adenoma Mammae (FAM). FAM is a benign tumor in the breast that is clearly defined and in the form of a movable lump. FAM usually occurs in young women, namely teenagers or around 20-25 years. The purpose of this study was to determine the characteristics of knowledge and attitudes of students of class XI SMK PGRI 2 about prevention of FAM. This study used a descriptive design with a cross sectional approach. The sampling technique was random sampling technique with a sample size of 49 respondents. The results of this study showed that 10 respondents had good knowledge (20.4\%), 17 respondents $(34.7 \%)$ had sufficient knowledge and 22 respondents (44.9\%) had insufficient knowledge. 22 respondents (44.9\%) had positive attitudes and 27 respondents (55.1\%) had negative attitudes. The conclusion of the study is that most of the respondents have poor knowledge of FAM prevention, namely as many as 22 respondents (44.9\%) and most respondents have negative attitudes about FAM prevention, namely 27 respondents (55.1\%). It is hoped that this research can be used as a guideline for early detection of breast abnormalities and to increase prevention of FAM.
\end{abstract}

Keywords: Knowledge, Attitude, Fibroadenoma mammae

\begin{abstract}
ABSTRAK
Salah satu penyakit tidak menular adalah Fibro Adenoma Mammae (FAM). FAM yaitu tumor jinak pada payudara yang berbatas jelas dan berbentuk benjolan yang dapat di gerakkan. FAM biasanya terjadi pada wanita usia muda, yaitu usia remaja atau sekitar 20-25 tahun. Tujuan dari penelitian ini untuk mengetahui Karakteristik pengetahuan dan sikap siswa 'kelas XI SMK PGRI 2 tentang pencegahan FAM. Penelitian ini menggunakan rancangan deskriptif dengan pendekatan cross sectional. Teknik pengambilan sampel teknik random sampling dengan jumlah sampel 49 responden. Hasil penelitian ini diperoleh responden memiliki pengetahuan baik sebanyak 10 responden $(20,4 \%)$, pengetahuan cukup sebanyak 17 responden $(34,7 \%)$ dan pengetahuan kurang sebanyak 22 responden (44,9\%). Responden memiliki sikap positif sebanyak 22 responden (44,9\%) dan memiliki sikap negatif sebanyak 27 responden $(55,1 \%)$. Kesimpulan penelitian yaitu sebagian besar responden berpengetahuan kurang baik tentang pencegahan FAM yaitu sebanyak 22 responden (44,9\%) dan sebagian besar responden memiliki sikap negatif mengenai pencegahan FAM yaitu sebanyak 27 responden $(55,1 \%)$. Diharapkan penelitian ini dapat dijadikan pedoman untuk mendeteksi secara dini adanya kelainan pada payudara dan meningkatkan pencegahan terhadap FAM.

Kata Kunci: Sikap, Pengetahuan, Fibroadenoma mammae
\end{abstract}




\section{PENDAHULUAN}

\section{LATAR BELAKANG}

Tumor payudara merupakan suatu kelainan yang paling penting yang dialami oleh perempuan. Salah satu jenis tumor jinak yang sering ditemukan pada perempuan adalah FAM. FAM memiliki karakter tidak nyeri, dapat digerakkan, berbatas tegas dan berkonsistensi padat kenyal ${ }^{1}$. Berdasarkan data dari international Agency for Riserch on Cancer (IARC) Tahun 2012, insiden kanker payudara sebesar 40/100.000 perempuan. Prevalensi penyakit kanker diindonesia cukup tinggi yaitu 1,4/1000 penduduk atau sekitar 330.000 orang mengidap kanker².

Data di Indonesia tentang FAM masih belum lengkap. Pertengahan tahun 2011 diperkirakan sebanyak 100 orang terkena tumor jinak payudara. FAM merupakan tumor jinak payudara yang sering terjadi pada wanita usia < 25 tahun. Insiden FAM menurun sesuai dengan peningkatan usia dan sebagian menurun saat menopause. FAM ini ditemukan dua kali lebih sering pada orang kulit hitam, pasien dengan kadar hormone tinggi (remaja dan wanita hamil), dan pasien yang mendapatkan terapi hormone estrogen ${ }^{1,2}$

Kesehatan reproduksi menurut Departemen Kesehatan Republik Indonesia adalah suatu keadaan sehat secara menyeluruh mencakup fisik, mental dan kedudukan sosial yang berkaitan dengan alat, fungsi serta proses reproduksi, dan pemikiran kesehatan reproduksi bukan hanya kondisi yang bebas dari penyakit, melainkan juga bagaimana seseorang dapat memliki seksual yang aman dan memuaskan sebelum dan sesudah menikah ${ }^{3}$.

Hasil penelitian Helfiana yang dirawat inap di RS Santa Elizabeth Medan tahun 20072011 diketahui proporsi tertinggi FAM berdasarkan umur adalah kelompok umur $<35$ tahun $(72,8 \%)^{4}$. Pemeriksaan payudara sendiri (SADARI) merupakan salah satu langkah deteksi dini untuk mencegah terjadinya kanker payudara yang akan lebih efektif jika dilakukan sedini mungkin mencapai usia reproduksi. $^{5}$
Minat masyarakat untuk melakukan pemeriksaan payudara masih sangat rendah, hal ini banyak dipengaruhi oleh ketidaktahuan wanita akan bahaya penyakit pada payudara, sedangkan pengetahuan masih dipengaruhi oleh pendidikan maupun ekonomi. Penyakit pada payudara yang salah satunya FAM dapat dicegah sedini mungkin dengan berbagai cara dan salah satunya yang paling efektif adalah denagn SADARI ${ }^{6}$.

SMK PGRI 2 Kota Jambi merupakan salah satu sekolah menegah kejuruan yang Meskipun tidak ada data pasti tentang siswa yang mengalami Fibroadenoma mammae (FAM) tetapi setiap tahun di laporkan bahwa ada siswa yang izin untuk menjalani operasi atau pengobatan Fibroadenoma mammae (FAM).

Data jumlah siswa SMK kelas XI PGRI 2 Kota Jambi adalah 246 orang dengan usia ratarata antara 16-17 tahun. Berdasarkan latar belakang tersebut peneliti tertarik untuk melakukan penelitian yang berjudul "Karakteristik Siswa SMK PGRI 2 Kota Jambi tentang Pencegahan Fibroadenoma mammae (FAM) .

\section{TUJUAN PENELITIAN}

Mengetahui karakteristik siswa SMK PGRI 2 Kelas XI tentang Pencegahan Fibroadenoma mammae (FAM).

\section{METODE PENELTIAN}

Penelitian ini merupakan metode deskriptif dengan pendekatan cross sectional yaitu suatu metode yang dilakukan dengan tujuan melihat karakteristik tentang suatu keadaan secara objektif (Notoatmodjo, 2010). Metode penelitian ini bertujuan untuk mengetahui bagaimana karakteristik siswa SMK PGRI 2 Kota Jambi tentang Pencegahan Fibroadenoma Mammae (FAM). Kemudian dicari independent variable-nya. Populasi yang dimaksud dalam penelitian ini adalah seluruh siswa Kelas XI SMK PGRI 2 Kota Jambi yang berjumlah 246 siswa. sampel yang dapat mewakili jumlah populasi sebanyak 49 orang. 
HASIL

Tabel 1

Distribusi jawaban responden pada setiap pertanyaanpengetahuan Siswa SMK PGRI 2 tentang pencegahan FAM

$n=49$

\begin{tabular}{|c|c|c|c|c|c|c|c|}
\hline \multirow[t]{3}{*}{ No } & \multirow{3}{*}{$\begin{array}{l}\text { Pertanyaan Tentang Pencegahan } \\
\text { Fibroadenoma mammae (FAM) }\end{array}$} & \multicolumn{6}{|c|}{ Pengetahuan } \\
\hline & & \multicolumn{2}{|c|}{ Benar } & \multicolumn{2}{|c|}{ salah } & \multicolumn{2}{|c|}{ Jumlah } \\
\hline & & $\mathbf{F}$ & $\%$ & $\mathbf{F}$ & $\%$ & $\mathbf{F}$ & $\%$ \\
\hline 1 & $\begin{array}{l}\text { Fibroadenoma Mamme (FAM) adalah tumor } \\
\text { jinak pada payudara }\end{array}$ & 31 & 63,3 & 18 & 36,7 & 49 & 100 \\
\hline 2 & $\begin{array}{l}\text { Usia wanita yang biasanya mengalami } \\
\text { fibroadenoma mammae (FAM) adalah wanita } \\
\text { usia muda 20-30 tahun }\end{array}$ & 27 & 55,1 & 22 & 44,9 & 49 & 100 \\
\hline 3 & $\begin{array}{l}\text { Tanda dan gejala Fibroadenoma mammae } \\
\text { (FAM) adalah adanya benjolan pada payudara } \\
\text { yang berbatas jelas dan bisa digerakkan }\end{array}$ & 33 & 67,3 & 16 & 32,7 & 49 & 100 \\
\hline 4 & $\begin{array}{l}\text { Yang tidak termasuk tanda dan gejala } \\
\text { fibroadenoma mammae (FAM) adalah benjolan } \\
\text { yang tidak dapat digerakkan }\end{array}$ & 23 & 46,9 & 26 & 53,1 & 49 & 100 \\
\hline 5 & $\begin{array}{l}\text { Faktor yang bukan penyebab fibroadenoma } \\
\text { mammae (FAM) adalah sel-sel kanker }\end{array}$ & 36 & 73,5 & 13 & 26,5 & 49 & 100 \\
\hline 6 & $\begin{array}{l}\text { Cara untuk medeteksi dini fibroadenoma } \\
\text { mammae (FAM) adalah dengan melakukan } \\
\text { SADARI }\end{array}$ & 34 & 69,4 & 15 & 30,6 & 49 & 100 \\
\hline 7 & $\begin{array}{l}\text { Hal yang dilakukan jika menemukan benjolan } \\
\text { pada payudara adalah melakukan pemeriksaan } \\
\text { lanjutan seperti mammografi }\end{array}$ & 27 & 55,1 & 22 & 44,9 & 49 & 100 \\
\hline 8 & $\begin{array}{l}\text { Hal yang tidak perlu dilakukan untuk mencegah } \\
\text { fibroadenoma mammae (FAM) adalah } \\
\text { menggunakan bra yang ketat }\end{array}$ & 21 & 42,9 & 28 & 57,1 & 49 & 100 \\
\hline 9 & $\begin{array}{l}\text { Tindakan yang dilakukan untuk penanganan } \\
\text { fibroadenoma mammae (FAM) adalah biopsy }\end{array}$ & 27 & 55,1 & 22 & 44,9 & 49 & 100 \\
\hline 10 & 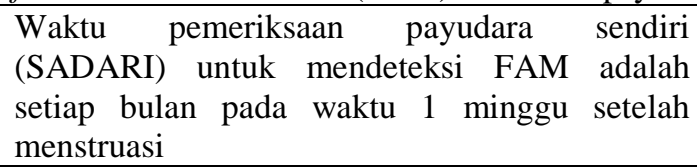 & 35 & 71,4 & 14 & 28,6 & 49 & 100 \\
\hline
\end{tabular}

Tabel 2

Distribusi jawaban responden pada setiap pertanyaan sikap Siswa SMK PGRI 2 tentang pencegahan FAM $n=49$

\begin{tabular}{|c|c|c|c|c|c|c|c|c|c|}
\hline \multirow{3}{*}{ No } & \multirow{3}{*}{ Pernyataan } & \multicolumn{8}{|c|}{ Sikap } \\
\hline & & \multicolumn{2}{|c|}{ SS } & \multicolumn{2}{|c|}{$\mathbf{S}$} & \multicolumn{2}{|c|}{ TS } & \multicolumn{2}{|c|}{ STS } \\
\hline & & $\mathbf{F}$ & $\%$ & $\mathbf{F}$ & $\%$ & $\mathbf{F}$ & $\%$ & $\mathbf{F}$ & $\%$ \\
\hline 1 & $\begin{array}{lcr}\text { Masalah } & \text { pada payudara } \\
\text { seperti } & \text { Fibroadenoma } \\
\text { mammae } & \text { (FAM) bisa } \\
\text { dideteksi sedini mungkin }\end{array}$ & 6 & 12,2 & 13 & 26,5 & 15 & 30,6 & 15 & 30,6 \\
\hline 2 & $\begin{array}{llr}\text { Pola hidup } & \text { sehat dan } \\
\text { pemeriksaan } & \text { payudara }\end{array}$ & 7 & 14,3 & 14 & 28,6 & 16 & 32,7 & 12 & 24,5 \\
\hline
\end{tabular}



Vol. 15 No. 3 September - Desember 2020

\begin{tabular}{|c|c|c|c|c|c|c|c|c|c|}
\hline & $\begin{array}{l}\text { sendiri (SADARI) secara } \\
\text { rutin merupakan salah satu } \\
\text { cara mendeteksi FAM }\end{array}$ & & & & & & & & \\
\hline 3 & $\begin{array}{lr}\text { Segera } & \text { berkonsultasi } \\
\text { kedokter dan melakukan } \\
\text { pemeriksaan lanjutan jika } \\
\text { menemukan } & \text { benjolan } \\
\text { dipayudara } & \end{array}$ & 7 & 14,3 & 17 & 34,7 & 15 & 30,6 & 10 & 20,4 \\
\hline 4 & $\begin{array}{l}\text { Fibroadenoma mammae } \\
\text { (FAM) merupakan tumor } \\
\text { jinak pada payudara bisa } \\
\text { disembuhkan dan tidak } \\
\text { menimbulkan kanker }\end{array}$ & 2 & 4,1 & 18 & 36,7 & 17 & 34,7 & 12 & 24,5 \\
\hline 5 & $\begin{array}{l}\text { Mengetahui faktor penyebab } \\
\text { fibroadenoma mammae } \\
\text { (FAM) akan membuat lebih } \\
\text { waspada dan rutin } \\
\text { melakukan pemeriksaan } \\
\text { payudara sendiri }\end{array}$ & 4 & 8,2 & 11 & 22,4 & 22 & 44,9 & 12 & 24,5 \\
\hline 6 & $\begin{array}{l}\text { Fibroadenoma mammae } \\
\text { (FAM) adalah penyakit yang } \\
\text { tidak berbahaya dan tidak } \\
\text { perlu penanganan apapun }\end{array}$ & 15 & 30,6 & 15 & 30,6 & 12 & 24,5 & 7 & 14,3 \\
\hline 7 & $\begin{array}{l}\text { Malu untuk berkonsultasi } \\
\text { kedokter ataupun petugas } \\
\text { kesehatan jika mengalami } \\
\text { benjolan dipayudara }\end{array}$ & 17 & 34,7 & 16 & 32,7 & 12 & 24,5 & 4 & 8,2 \\
\hline 8 & $\begin{array}{l}\text { Tidak perlu mencari tahu } \\
\text { penyebab, tanda dan gejala } \\
\text { fibroadenoma mammae } \\
\text { (FAM) karena tidak terlalu } \\
\text { penting dan berbahaya }\end{array}$ & 12 & 24,5 & 15 & 30,6 & 12 & 24,5 & 10 & 20,4 \\
\hline 9 & $\begin{array}{lr}\text { Tidak suka melakukan } \\
\text { pemeriksaan } & \text { payudara } \\
\text { sendiri (SADARI) } & \text { karena } \\
\text { risih melakukannya } & \end{array}$ & 12 & 24,5 & 18 & 36,7 & 15 & 30,6 & 4 & 8,2 \\
\hline 10 & $\begin{array}{l}\text { Membiarkan } \\
\text { dipayudara akan menjolan } \\
\text { benjolan itu hilang dengan } \\
\text { sendirinya }\end{array}$ & 13 & 26,5 & 15 & 30,6 & 11 & 22,4 & 10 & 20,4 \\
\hline
\end{tabular}


Dari hasil penelitian didapat hasil sebagian besar atau mayoritas responden berpengetahuan kurang yaitu sebanyak 44,9\%, responden berpengetahuan cukup sebanyak 34,7\% sedangkan hanya $20,4 \%$ responden yang berpengetahuan baik.

\section{PEMBAHASAN}

Masih banyak reponden yang pengetahuannya kurang baik daripada responden yang berpengetahuan baik dapat disebabkan karena kurangnya keinginan mencari informasi tentang fibroadenoma mammae (FAM) terutama dalam deteksi dini baik gejala dan penyebab serta pencegahan FAM. Menurut peneliti rendahnya pengetahuan responden itu kemungkinan disebabkan kurangnya kesadaran responden tentang pentingnya mengetahui tentang pencegahan fibroadenoma mammae dan kurangnya informasi yang diperoleh, karena masalah Fibroadenoma mammae (FAM) masih jarang dibahas secara keseluruhan.

Hasil penelitian ini sejalan dengan penelitian yang dilakukan oleh Cholifah (2019) yang menunjukkan sebagian besar pengetahuan responden tentang FAM adalah tidak baik sebanyak 26 responden $(86,7 \%)$ dan sebagian besar sikap responden tentang FAM adalah negatif sebanyak 21 responden $(70,0 \%)^{7}$.

FAM dapat disebabkan dari riwayat keluarga, terlalu sering memakan makanan fast food, merokok dan minuman alcohol, dan lain-lain. Makanan fast food ternyata mengandung garam, lemak, dan kalori yang tinggi termasuk kolesterol yang mencapai $70 \%$ serta hanya sedikit mengandung serat yang justru sangat dibutuhkan oleh tubuh ${ }^{8,9}$. Berdasarkan Sinaga (2016) yang menyatakan ada hubungan pengetahuan dan sikap remaja puteri tantang deteksi dini kanker payudara melalui SADARI ${ }^{9}$.

Untuk meningkatkan pengetahuan responden tentang pencegahan fibroadenoma mammae (FAM) diperlukan adanya peyuluhan kesehatan reproduksi tentang fibroadenoma mammae (FAM) baik penyebab, gejala, faktor penyebab dan yang terpenting adalah pencegahan FAM. Pemeriksaan payudara sendiri sangat diperlukan dalam mendeteksi dini adanya FAM pada payudara ${ }^{5,6}$.

Menurut peneliti, hal ini berarti tingginya sikap negatif responden pencegahan fibroadenoma mammae (FAM) karena kurangnya sikap yang baik tentang mengatasi masalah pada payudara dan merasa malu untuk berkonsultasi jika menemukan benjolan dipayudara serta merasa tidak suka dan risih jika melakukan SADARI.

Perilaku pencegahan penyakit FAM dipengaruhi juga oleh sikap terhadap FAM. Sikap akan menentukan pola fikir remaja untuk dapat menerima informasi baru terkait FAM. Sikap remaja yang mendukung terhadap pencegahan penyakit FAM akan mempengaruhi kemauan remaja untuk melakukan praktik pencegahan penyakit $\mathrm{FAM}^{2,7}$.

\section{SIMPULAN}

Sebagian besar responden berpengetahuan kurang baik tentang pencegahan fibroadenoma mammae (FAM) yaitu sebanyak 22 responden $(44,9 \%)$. Sebagian besar responden memiliki sikap negatif mengenai pencegahan fibroadenoma mammae (FAM) yaitu sebanyak 27 responden $(55,1 \%)$.

\section{DAFTAR PUSTAKA}

1. Alini, Widya L. Faktor-Faktor yang Menyebabkan Kejadian Fibroadenoma mammae (FAM) pada Pasien Wanita yang Berkunjung di Poliklinik Spesialis Bedah Umum RSUD Bengkalis. J Ners. 2018;2(1):110.

2. Floreska A. Perilaku Pencegahan Penyakit Fibroadenoma mammae Di Ma. Brave J. 2013;1:1-4. amaliafloreska95@gmail.com

3. Direktorat Kesehatan Keluarga Kementerian Kesehatan RI. Upaya Pemenuhan Hak Kesehatan Reproduksi Melalui Pelayanan Kesehatan Reproduksi Terpadu (PKRT).; 2017.

4. Agustina Sidauruk H. Karakteristik Penderita Fibroadenoma mammae (Fam) Rawat Inap Di Rs Santa Elisabeth Medan Tahun 2007-2011. Published online 2011.

5. Pamungkas Z. Deteksi Dini Kanker Payudara. Nuha Medika; 2011.

6. Olfah Y. Kanker Payudara Dan SADARI. Nuha Medika; 2013.

7. Cholifah N dkk. H UBUNGAN T INGKAT P ENGETAHUAN D AN S IKAP W ANITA U SIA S UBUR D ENGAN K EJADIAN F IBROADENOMA M AMMAE ( F AM ) D I Klinik Dr.Handy SS, SP.B Kudus. 2019;10(2):338-342.

8. Anis Nikmatul N. Pengaruh Pelatihan SADARI Melalui Pendidik Sebaya (Peer Group) Terhadap Ketrampilan Deteksi Dini Fibroadenoma mammae (FAM) Pada Remaja. J Ilm Kesehat. 2018;XI(I):313-320.

9. Sinaga CF, Ardayani T. Hubungan Pengetahuan Dan Sikap Remaja Putri Tentang Deteksi Dini Kanker Payudara Melalui Periksa Payudara Sendiri Di Sma Pasundan 8 Bandung Tahun 2016. Kartika J Ilm Farm. 2016;4(1):16-19. doi:10.26874/kjif.v4i1.52 